\title{
A theory of 'authorship transfer' and its application to the context of Artificial Intelligence creations
}

\author{
Bingbin Lu \\ Professor, Law School, Nanjing University
}

This article aims to contribute to the copyright debate concerning Artificial Intelligence ('AI') creations. AI-created works could and should be protected by copyright law. However, existing answers to the issue of allocation of authorship remain somewhat unsatisfactory. A reasonable and practical solution to this issue, fortunately, could be established upon the doctrine of 'authorship transfer' (the initial transfer of authorship from the actual creator to a constructive author) in modern copyright law. The 'control of the creative process' theory can provide a reasonable and justifiable explanation of 'authorship transfer'. The person, either a natural or a juridical one, who has exercised sufficient control over the creative process, should be constructed as an author of the outcome. This theory is quite flexible before the ever-changing AI technology that challenges copyright law. For AI-created works, the authorship is better transferred to a person behind the AI who had control over the creative process in order to safeguard the current copyright system and its founding principles.

Keywords: Artificial Intelligence (AI), authorship transfer, control, copyright, creative process

\section{INTRODUCTION}

Artificial intelligence ('AI') is an exciting and revolutionary technology designed to imitate or simulate human intelligence, the continued and exponential growth of which will undeniably and deeply impact society. One noticeable impact is on copyright law, because AI may possess creativity, or more accurately, computational or algorithmic creativity, which is capable of generating creative outputs similar to those derived from human biological intelligence. As one author observed, 'Humans are no longer the only source of innovative and creative works'. ${ }^{1}$ As AI continues to evolve, it even has the prospect of becoming a major actor in the creative process and the main force for advancing innovation and creation in our society.

Legal issues immediately arise. Should copyright law protect outputs generated by AI? If so, who should be the author and/or copyright holder? In the main legal jurisdictions and possibly leading countries or regions in AI technology, including Europe, the United States and China, the copyright issues regarding AI creation have already been discussed, though without an agreed solution. The UK is the pioneer in providing

1. K Hristov, 'Artificial Intelligence and the Copyright Dilemma' (2017) 57 IDEA: J. Franklin Pierce for Intell. Prop. 431, 452. 
copyright protection for Computer-Generated Works (CGWs). ${ }^{2}$ Some scholars believe that the existing CGWs regime can be extended to AI-generated works. ${ }^{3}$ Despite this, disagreements still exist, ${ }^{4}$ and the rare judicial interpretation of these CGWs rules provide little guidance on whether and how these rules can be applied to AI creations. In the EU, in a resolution on 16 February 2017, the European Parliament called upon the Commission to address whether and how the existing intellectual property law, including copyright law, should be adjusted to the emerging AI technology and the forthcoming AI era. ${ }^{5}$ In the US, over thirty years ago, the 1978 CONTU report officially raised the issue of CGWs, ${ }^{6}$ upon which scholars and commentators continue to debate. ${ }^{7}$ In China, with its aspiration to become a global leader in AI technology, ${ }^{8}$ scholars are also debating the copyright issues of AI-created works. ${ }^{9}$ This article concentrates more on theory than positive law, partly by examining worldwide academic discussion, but a comparative legal analysis of the above-mentioned jurisdictions will also be conducted.

Among other aspects of AI-copyright concerns, this article focuses on the assignment of authorship. Twenty-five years ago, Professor Miller proposed that there should be no obstacle to CGWs obtaining copyright protection; on the contrary, it is the question of authorship that demands more attention. ${ }^{10}$ This conclusion so far holds true in our new AI era.

AI is a broad topic and it further includes weak AI, strong AI and possible Artificial Superintelligence (ASI) in the future. ${ }^{11}$ People use weak AI in a tool sense and the authorship of creations with the assistance of this type of AI is more easily solved under current copyright law since people have also used other tools in the act of creation

2. See Copyright, Designs and Patents Act (Eng.), 1988, s 9(3), s 178. This article will further discuss these provisions in sections 2.2.2 and 4 .

3. See, for example, A Guadamuz, 'Do Androids Dream of Electric Copyright? Comparative Analysis of Originality in Artificial Intelligence Generated Works' 2017(2) IPQ 169, 185-6.

4. See, for example, A Ramalho, 'Will Robots Rule the (Artistic) World? A Proposed Model for the Legal Status of Creations by Artificial Intelligence Systems' (2017) 21(1) Journal of Internet Law 11, 11-25 (proposing a sort of 'disseminator's right' to solve the copyright dilemma of AI creation).

5. See European Parliament resolution of 16 February 2017 with recommendations to the Commission on Civil Law Rules on Robotics (2015/2103(INL)), paras 18-21.

6. See National Commission on New Technological Uses of Copyrighted Works, Final Report (the CONTU Final Report) (CONTU 1979) 43-6.

7. See, for example, J Grimmelmann, 'There's No Such Thing as a Computer-Authored Work - and It's a Good Thing, Too' (2016) 39 Colum. J.L. \& Arts 403; ME Kaminski, 'Authorship, Disrupted: AI Authors in Copyright and First Amendment' (2017) 51 U.C. Davis L. Rev. 589.

8. See D Cyranoski, 'China Enters the Battle for AI Talent' (2018) 53 Nature 260-61.

9. According to the search results of CNKI (a Chinese academic journals database), there were five papers on AI and copyright published in the Chinese core journals (CSSCI) in 2017, 23 in 2018 and 39 in 2019, indicating that it has been a heated topic to which attention is continuously growing.

10. See AR Miller, 'Copyright Protection for Computer Programs, Databases, and ComputerGenerated Works: Is Anything New Since CONTU?' (1993) 106 Harv. L. Rev. 977, 1045.

11. See J Kerns, 'What's the Difference Between Weak and Strong AI?' (15 February 2017) $<$ https://www.machinedesign.com/markets/robotics/article/21835139/whats-the-differencebetween-weak-and-strong-ai> accessed 16 January 2020; T Urban, 'The AI Revolution: The Road to Superintelligence' (22 January 2015) <https://waitbutwhy.com/2015/01/artificial-intelligencerevolution-1.html> accessed 16 January 2020. 
for a long time. What is challenging and problematic is strong AI or even ASI, which is not a tool in a traditional sense. Who should have copyright for a result created by strong AI or ASI?

This article will therefore further focus on AI in a non-tool sense. In this context, $\mathrm{AI}$ is actually the real author of an outcome. I propose that with a theory of 'authorship transfer' (transferring the authorship from the real author to a legally constructive one), AI creations in a non-tool sense, could be integrated into current legal systems without utterly demolishing our carefully principled foundations. I believe that the current copyright system is flexible enough for AI-created work if supported by an 'authorship transfer' theory. This article is thus dedicated to tailoring a reasonable theory of 'authorship transfer' (section 2) and to applying it to the context of AI creations (section 3).

\section{FORMULATING A NEW THEORY OF 'AUTHORSHIP TRANSFER'}

\subsection{The concept of author and the basic principle of authorship}

\subsubsection{The lack of an international consensus on the concept of author}

Before discussing the doctrine and theories of 'authorship transfer', it is worthwhile inspecting the basic concept of 'author'.

The most prominent international convention on copyright, the Berne Convention, ${ }^{12}$ does not provide guidance as to the definition and qualification of the fundamental term 'author', largely leaving the issue to Member States' discretion, which, as the Berne Convention Guide explains, is because 'national laws diverge widely, some recognizing only natural persons as authors, while others treat certain legal entities as copyright owners' ${ }^{13}$ This silence of the Berne Convention on the definition of the author indicates the lack of global consensus on this matter, and the entire dependency of the concept of authorship on national laws. ${ }^{14}$

However, related to the subject of this article, scholars, legislators and courts generally consent to at least one basic limitation of the term 'author', namely human authorship.

\subsubsection{The principle of human authorship}

It is established that the author must be a human being or a group of human beings. Professor Ricketson analysed the concept of authorship in the Berne Convention and concluded that the Convention requires human authorship, and the special treatment of cinematographic works is an exception to the general requirement of human authorship. ${ }^{15}$ Traditional copyright law insists on human authorship, and

12. Berne Convention for the Protection of Literary and Artistic Works (Paris Act of July 24, 1971, as amended on September 28, 1979).

13. World Intellectual Property Organization, Guide to the Berne Convention (WIPO 1978)

11.

14. See G Dutfield and U Suthersanen, Global Intellectual Property Law (Edward Elgar, Cheltenham 2008) 84.

15. See S Ricketson, 'People or Machines? The Berne Convention and the Changing Concept of Authorship' (1991-1992) 16 Colum - VLA J L \& Arts 1, 11, 21-2. 
thus 'copyright extends only to works of human authors'. ${ }^{16}$ Under this ideology of human authorship, naturally, it is believed that computer-generated outputs or automated products shall not receive copyright protection. ${ }^{17}$

Conventionally, the world's two major copyright systems diverge significantly on the role of personality in copyright law. ${ }^{18}$ In the civil law countries, the theoretical justification for protecting the author's right is to protect the artistic personality of an author injected into his or her copyrightable work. It is further demonstrated by civil law countries' protection of moral rights, a bundle of rights designed to protect the author's personhood. Based upon the personal bond between the work and the author, ${ }^{19}$ the moral rights attach utter significance to the protection of the inherent dignity of the author. ${ }^{20}$ In summary, the author's right system in civil law countries places greater emphasis on human authorship.

By taking a more economic legal approach, the copyright system in the common law world differs from the above in the role of the personality of the author in copyright doctrines. ${ }^{21}$ Nevertheless, the human authorship requirement plays a role in this system. For example, in the US, while the Copyright Act does not explicitly define the term of author, the US Copyright Office still explicitly stresses the human authorship requirement. ${ }^{22}$ In judicial practice, it is also stated that a certain element of human creativity must exist for a work to be copyrightable. ${ }^{23}$ The famous monkey selfie dispute also clearly shows the requirement of human authorship. ${ }^{24}$ In December 2014, shortly after the monkey selfie dispute caused widespread media attention, the US Copyright Office revised its Compendium of practice, highlighting the requirements of human authors, and added a list of examples of unprotected works, at the top of which is 'a photograph taken by a monkey'. ${ }^{25}$ The Northern District Court of California in the Naruto v Slater case, based on the Compendium of the Copyright Office, concluded that Naruto, a crested macaque monkey, cannot be an author in the sense of copyright law. ${ }^{26}$ Finally, the Federal Circuit Court upheld the decision of the District Court and concluded that, as a non-human, the monkey does not have a legal status under the Copyright Act. ${ }^{27}$

Nevertheless, there remain scholars who do not endorse the necessity of the human authorship requirement. For example, Professor Abbott asserts that the human authorship requirement is wrong and misguided because it discourages creations

16. WF Patry, Patry on Copyright (Thomson West 2016) vol. 2, § 3:45.

17. P Goldstein (ed), Goldstein on Copyright (Wolters Kluwer 2005, Supplement No. 5/2018, May 2018) § 2.2.2.

18. See Miller, supra (n 10) at 1049.

19. See M Perraki, 'Moral Rights: Could There Be a European Harmonisation - A Comparative Study of the Common Law and Civil Law Approach' (2000) 53 RHDI 329, 334.

20. See A Drassinower, 'Copyright Is Not about Copying' (2011-2012) 125 Harv. L. Rev. F. 108.

21. Perraki, supra (n 19), at 338.

22. US Copyright Office, Compendium of US Copyright Office Practices (3rd ed., 2014, revised 09/29/2017) § 306 (entitled 'The Human Authorship Requirement') <https://www.copyright.gov/ comp3/> accessed 3 March 2018.

23. Urantia Found. v Maaherra, 114 F.3d 955, 958 (9th Cir. 1997).

24. See 'Monkey Selfie Copyright Dispute' <https://en.wikipedia.org/wiki/Monkey_selfie_ copyright_dispute\#cite_ref-PolicyReview_2-1> accessed 3 March 2019.

25. US Copyright Office, Compendium, supra (n 22) § 313.2.

26. Naruto v Slater, No. 15-cv-04324-WHO, 2016 WL 362231, at 4 (N.D. Cal. Jan. 28, 2016).

27. Naruto v Slater, 888 F.3d 418, at 420 (2018). 
by non-human actors. ${ }^{28}$ Meanwhile, some scholars more specifically termed human authorship as 'romantic' authorship. ${ }^{29}$ For instance, Professor Jaszi argues that the 'romanticized vision of authorship' is highly likely to mislead legislation and judicial systems facing new technologies. ${ }^{30}$

This article agrees to maintain the human authorship requirement because, under current legal systems, only human beings can hold legal rights and assume legal obligations, while non-humans simply are not admitted to be the holders of copyright - a legal right.

So, the authorship of AI creation is better assigned to a person behind the AI who exerted supervision or control during the work's embodiment and thus justifies such an assignment. Before drawing a definitive conclusion, it is helpful to firstly explore the doctrine and theories of 'authorship transfer'.

\subsection{Doctrine and existing theories of 'authorship transfer'}

\subsubsection{Defining 'authorship transfer'}

'Authorship transfer', a term this article uses, refers to the initial transfer of authorship from an actual creator to a constructive author. The term is to be distinguished from 'copyright transfer', which refers to the subsequent transfer of ownership of a valid copyright from one party to another party. In the latter case, the transferor is entitled to fundamental freedom to dispose of his own rights, which positive law itself is sufficient to justify. What deserves to be theoretically explored is the initial transfer of authorship.

\subsubsection{Sample rules of presumed transfer of authorship}

A typical example of presumed transfer of authorship can be found in rules of works made for hire in the US and some other jurisdictions.

As a special arrangement to authorship, the doctrine of works made for hire has not been integrated into international law. ${ }^{31}$ The works made for hire rule usually exists in common law countries. Moreover, the United States takes an extreme approach to treating employers as authors, not just as initial owners. Section 201(b) of the US Copyright Act states, 'in the case of a work made for hire, the employer or other person for whom the work was prepared is considered the author for purposes of this title'. ${ }^{32}$ The authorship of such a work is transferred and copyright is granted to a party who did not directly formulate the expression of the work.

Since civil law countries theoretically link copyright to personhood, a legal person by default cannot be the author and the first holder of the copyright, as it is not an individual. However, some countries in the civil law family also adopted the works made for hire doctrine. In Japan, a legal person can qualify as an author of the works made

28. See R Abbott, 'I Think, Therefore I Invent: Creative Computers and the Future of Patent Law' (2016) 57 B.C. L. Rev. 1079, 1121.

29. See, for example, J Grimmelmann, 'Copyright for Literate Robots' (2015-2016) 101 Iowa L. Rev. 657, 658.

30. See P Jaszi, 'On the Author Effect: Contemporary Copyright and Collective Creativity' (1992) 10 Cardozo Arts \& Ent. L.J. 293, 320.

31. See Dutfield and Suthersanen, supra (n 14) at 85.

32. See 17 USC $§ 201$ (b) (2012). 
for hire, ${ }^{33}$ which diverges from personhood theory. Similarly, the Chinese Copyright Law, or more accurately as it is translated into the Law of Author's Rights, as a system imported from western tradition by legal transplantation, ${ }^{34}$ generally follows the author's rights system, yet at the same time exhibits the characteristics of the copyright system. Notably, it diverges from the author's rights system in its recognition of juridical authorship. The definition of author in China recognizes juridical persons or other organizations as well as a category of 'works of juridical persons', ${ }^{35}$ corresponding to the works for hire doctrine in the United States. It could be safely concluded that corporate authorship exists in both Japan and China, with the employer (ie the corporate) legally constructed as an author.

Under UK law, the initial ownership of a literary, dramatic, musical or artistic work made for hire, but not the authorship, will be attributed to the employer. ${ }^{36}$ Therefore, the UK rule of works made for hire does not follow the approach of authorship transfer. But in the UK law, there is at least one special rule, the author rule of CGWs, which reflects the presumed transfer of authorship. According to the UK's groundbreaking legislation on CGWs, a CGW is an original work produced by a computer 'such that there is no human author', ${ }^{37}$ and its author is legally constructed as 'the person by whom the arrangements necessary for the creation of the work are undertaken'. ${ }^{38}$ A number of common law jurisdictions also follow such rules. ${ }^{39}$ In essence, the authorship of CGWs is transferred from a non-human 'author' 40 to a person. Professor Ricketson stated that the British rule is anomalous under the human authorship requirement of the Berne Convention and is a clear exception to the general requirement. ${ }^{41}$ Ramalho also commented that this is a derogation from the general rule of authorship. ${ }^{42}$

Questions will arise regarding the rationality of this solution and the criteria for determining whether the 'necessary arrangements' are met. Theoretically, do the special rules of CGWs in these countries have the same theoretical basis as the works made for hire rule in the US? Or, should we find a different theory to explain the special treatment of CGWs? Practically speaking, various potential candidates, including the programmer, the user, the software selector or the investor may become the person making the necessary arrangements, ${ }^{43}$ then how to assess the criteria of 'necessary arrangements' and who should be considered the author? The answer is not as simple as the authorship issue of films or sound recordings, because in a movie or sound recording, the person

33. See Copyright Law of Japan, art $15<\mathrm{http} / /$ www.cric.or.jp/english/clj/cl2.html > (English translation) accessed 3 March 2018.

34. See Y Li, 'Transplantation and Transformation: 30-Year Development of China's IP System', in G Yu (ed), The Development of the Chinese Legal System: Change and Challenges (Routledge 2012) 149.

35. Copyright Law of the People's Republic of China (2010 Amendment), art 11.

36. Copyright, Designs and Patents Act (Eng.), 1988, s 11(2).

37. Ibid s 178.

38. Ibid s 9(3).

39. See Copyright Ordinance (Hong Kong) s 11(3); Copyright Act 1994 (New Zealand) s 5(2)(a); Copyright Act 1957 (India) s 2(d)(vi); Copyright and Related Rights Act 2000 (Ireland) s 21(f).

40. The 'author' here is not meant in a legal sense, but in the usual sense; a computer or AI can be considered as the real author or actual creator of a work in the usual sense.

41. See Ricketson, supra (n 15) at 11, 29.

42. Ramalho, supra (n 4) at 17.

43. See J McCutcheon, 'The Vanishing Author in Computer-Generated Works: A Critical Analysis of Recent Australian Case Law' (2013) 36 Melbourne University Law Review 915, 959; see also Ramalho, supra (n 4) at 17. 
making the necessary arrangements is usually the commercial 'producer' responsible for making the work. However, there are usually more people involved in the production of CGW, and it is not always correct to treat the investor as the author. The existing judicial practice of the British CGW rules, Nova Productions Ltd v Mazooma Games $L t d,{ }^{44}$ did distinguish between the contribution of the necessary arrangements and the input of skill or labour of an artistic kind, ${ }^{45}$ but provided few guidelines on how to judge the qualification of 'necessary arrangements'. Practical problems are closely related to theoretical issues. This article will first explore the theoretical issues, and then look for a test of 'necessary arrangements' or the degree of control in the language of this article.

\subsubsection{Scarce theories on 'authorship transfer'}

Theories on authorship transfer are remarkably scarce. Ostensibly, in works made for hire, the employment relationship per se could provide an explanation for the authorship transfer for these works, but the exact logic of why such an employment relationship can trigger the initial passage of authorship from one party to another remains ambiguous.

One prevalent explanation focuses on the reward to investment. Professor Ginsburg reasons, 'The work for hire doctrine rests on the grounds of facilitation of investment and exploitation. ${ }^{46}$ Other scholars also agree that the purpose of this doctrine is to promote and protect the business investment. ${ }^{47}$ It is argued that the employer has a substantial financial interest in the creation of the work, ${ }^{48}$ and the works for hire doctrine is a mechanism to encourage the employer to take the risk of commercial failure and assure themselves that their investment interest could also be a source of profit. ${ }^{49}$ Essentially, this explanation follows the road of the instrumental approach by viewing copyright as an instrument to promote investment in the creative industry.

\subsubsection{The defects of the investment protection theory}

The 'investment protection' theory can indeed explain the initial transfer of authorship in copyright law, but it is not without flaws.

First of all, this investment protection theory is disassociated from both utilitarianism and the theory of natural rights, which respectively support the two major copyright systems in the world. Utilitarianism views copyright law as a stimulator of the creation of intellectual products, while the theory of natural rights perceives copyright law as the protector of the product of intellectual labour. Unfortunately, neither theory copes with investment protection perfectly. Once the theory of investment protection

44. Nova Productions Ltd v Mazooma Games Ltd. [2006] RPC 379.

45. Ibid 399 [106].

46. JC Ginsburg, 'The Concept of Authorship in Comparative Copyright Law' (2003) 52 DePaul L. Rev. 1064, 1088.

47. See, for example, NB Schaumann, 'Small Business and Copyright Ownership' (1996) 22 Wm. Mitchell L. Rev. 1469, 1482; JL Schwab, 'Audiovisual Works and the Work for Hire Doctrine in the Internet Age' (2011) 35 Colum. J.L. \& Arts 141, 149.

48. JB Wadley and JM Brown, 'Working between the Lines of Reid: Teachers, Copyrights, Work-for-Hire and a New Washburn University Policy' (1999) 38 Washburn L.J. 385, 429.

49. See MR Harris, 'Copyright, Computer Software, and Work Made for Hire' (1990) 89 Mich. L. Rev. 661, 662. 
has been introduced, utilitarian copyright law hesitates between stimulating the intellectual creation and protecting the economic investment. Meanwhile, while the theory of natural rights advocates mechanisms such as the automatic copyright protection upon a work's completion, it cannot solve the relationship between labour, capital and other production factors in the allocation of property rights.

Second, overemphasis of this theory could easily mislead an audience to consider copyright law an 'investor protection law', contrary to the tenet of copyright law as a 'creation protection law' or an 'intellectual property protection law'. Construing copyright law as an 'investor protection law' would fundamentally shake its foundations by demanding an utter revolution of current copyright norms.

Third, at most, the investment rationale can only provide a partial explanation for copyright authorship. The investment rationale is most suited for entrepreneurial works as a company has a commercial interest in producing such works. The UK law distinguishes between authorial works and entrepreneurial works, or content copyright and signal copyright. ${ }^{50}$ In the case of entrepreneurial works (including sound recordings, films, broadcasts and the typographic arrangements of a published edition), those who invest in making such works are directly considered authors. ${ }^{51}$ Judge Arnold believes the distinction between these two categories is entirely reasonable as the first one is based on the protection of creativity and the second is based on investment protection. ${ }^{52}$ Judge Arnold once again stated in England and Wales Cricket Board Ltd \& Anor v Tixdaq Ltd \& Anor that the rationale for protecting entrepreneurial copyrights such as broadcasts and films is 'the investment made by the broadcaster or producer' ${ }^{53}$ Although the investment justification is a sound practical reason for entrepreneurial works, one should be cautious about extending this justification to all kinds of works. The distinction between authorial works and entrepreneurial works in the UK suggests that the reward for skill, labour and creativity is a more rational explanation for authorial works, that is, literary, dramatic, musical and artistic works.

Further, the investment rationale cannot fully explain the authorship of CGWs and AI creations. The UK's CGWs regime shifts the authorship of such works from nonhumans to those who make the necessary arrangements for the creative process. What needs to be clear is that 'necessary arrangements' are not equal to 'investments'. For example, a person can borrow an AI system from his or her friends for free, that is, no investment is made, but this user may satisfy the 'necessary arrangements' requirement and become an author. Another problem is that in most cases, it can be said that both the programmer and the user may have invested in creative computer software or an AI system, so whose investment should be rewarded and protected? The programmer and the user are often in distinct positions, making it difficult to form a collaboration and co-authorship, and it is not always fair to decide the relevant controversy based on the amount of money invested, because in most cases, the programmer's investment

50. See R Arnold, 'Content Copyrights and Signal Copyrights: The Case for a Rational Scheme of Protection' (2011) 1 QMJIP 272, 276-7; see also J Haynes, 'Subject Matter of Copyright Protection in the UK: A Road Map to Effectuating Statutory Reform' (2013) 39(2) Commonwealth Law Bulletin 319, 319-32.

51. Copyright, Designs and Patents Act (Eng.), 1988, s 9. It should be noted that the authorship of entrepreneurial works in UK law is directly accredited to the commercial producer rather than through a mechanism of transferring the authorship from the real creator to a legally constructed author, so it is different from the 'authorship transfer' concept as discussed in this article.

52. See Arnold, supra (n 50) at 276-7.

53. England and Wales Cricket Board Ltd \& Anor v Tixdaq Ltd \& Anor [2016] EWHC 575 (Ch) at [66]. 
will exceed the user's cost of purchasing an AI system. It is necessary to find a better theory that can provide a systematic and reasonable explanation for copyright authorship, especially for authorship transfer.

In a nutshell, the investment protection theory lacks the support of the basic principles of copyright law and does not provide a complete explanation for copyright authorship. What this article wishes to propose, therefore, is a new theory of "control of the creative process' inherent in current copyright philosophy to explain the transfer of authorship.

\subsection{The 'control of the creative process' theory}

\subsubsection{Control and authorship in general}

In traditional authorship determination, control is an essential element. The control test is a universal one for determining authorship, suggested by Professor Ginsburg, who examined dominant legal systems before concluding that they appear to agree that an author is a human being who exercises subjective judgment in composing the work and who controls its execution. ${ }^{54}$ It is undeniable that an author should control his or her selection, arrangement and judgment of words or any other expressive element. This control test applies not only to single authorship, but also to special ones such as joint authorship and works made for hire.

For joint authorship, although different countries will have different definitions and tests to determine it, they have in common that the concept of control plays a key role in judging the status of co-authors. In the UK, joint authorship is defined as 'a work produced by the collaboration of two or more authors in which the contribution of each author is not distinct from that of the other author or authors'. ${ }^{55}$ 'Control' plays a key role in assessing 'collaboration' and/or 'right kind of skill and labour' to form authorship and originality. ${ }^{56}$ For example, in Hadley $v$ Kemp, a music copyright case, because the defendant had a hierarchy control and a tight control over the band, the other members of the band would obey him, with the defendant in charge of how the songs should sound, and no collaboration was found between plaintiff and defendant, thereby precluding the possibility of co-authorship. ${ }^{57}$ In the US, joint work is defined as 'a work prepared by two or more authors with the intention that their contributions be merged into inseparable or interdependent parts of a unitary whole'. ${ }^{58}$ Courts have to find objective evidence to decide the key element of 'intention'. In doing so, judges will look into evidence including the putative co-author's decision-making authority. ${ }^{59}$ And, in determining co-authorship, 'control in many cases will be the most important factor' ${ }^{60}$ Under such a test, if a person has no decision-making authority or control over the final work, that person cannot become a co-author.

For works made for hire, the idea of control has also influenced the judicial standard for determining the status of an employer. The American rule of 'works made for hire' is

54. See Ginsburg, supra (n 46) at 1067.

55. Copyright, Designs and Patents Act (Eng.) 1988, s 10(1).

56. See L Biron and E Cooper, 'Authorship, Aesthetics and the Artworld: Reforming Copyright's Joint Authorship Doctrine' (2016) 35(1) Law and Philosophy 55, 72.

57. See Hadley v Kemp, EMLR 589 (Ch. 1999), at 641.

58. 17 USC $\S 101$ (1976).

59. Thomson v Larson, 147 F.3d. 195, 202 (2nd Cir. 1998).

60. Aalmuhammed v Lee, 202 F.3d 1227, 1234 (2000). 
a major exception to the creative doctrine that gives the actual creator copyright. ${ }^{61}$ 'This legal fiction finds its roots in the notion of control or agency. ${ }^{62}$ To elaborate, it is the controller of a work made for hire, instead of its actual creator, who would be deemed to be the author. The element of control is essential for this employer-employee relationship. To determine whether a party is an employee, the US Supreme Court held that the term 'employee' should be understood according to the general common law of agency. ${ }^{63}$ In assessing the employer-employee relationship, the general common law of agency will consider a multitude of factors, one decisive factor being 'the hiring party's right to control the manner and means by which the product is accomplished' ${ }^{64}$ rather than a right to control the product or a requirement for actual control. ${ }^{65}$ Earlier, different US courts used different tests, mainly the 'right to control' test and the 'actual control' test. The Supreme Court harmonized and improved these tests through the agency law test with its 'right to control' element. ${ }^{66}$ The agency law test will 'inevitably entail the determination whether the contributor was subject to the hiring party's control' ${ }^{67}$ All in all, the idea of control has always been at the heart of works made for hire and a decisive factor for such works. It is reasonable to formulate a control theory to explain the phenomenon of authorship transfer and apply it to new situations such as AI creations.

\subsubsection{A new explanation of 'authorship transfer': the 'control of the creative process' theory}

The control test conventionally concentrates on the creation and fixation of the expression itself, ${ }^{68}$ rather than on the overall creative process. This article proposes a modified version of the control test in the new theory 'control of the creative process'.

Under this new theory, the controller of the creative process will be the right holder and this can provide a rational explanation for the authorship transfer phenomenon. For works made for hire, the object of control is 'the manner and means by which the product is accomplished', ${ }^{69}$ which implies the creative process. The employer could be deemed as the controller of the creative process, and the authorship of the employee's work is transferred from the actual creator (the employee) to the controller of the creative process (the employer). The value of this new theory can be better reflected in the issue of non-human created works. Here is a preliminary analysis.

61. J Seignette, Challenges to the Creator Doctrine, Authorship, Copyright Ownership and the Exploitation of Creative Works in the Netherlands, Germany and the United States (Kluwer Law International 1994) 36, 38.

62. Ramalho, supra (n 4) at 18.

63. Community for Creative Non-Violence et al. v Reid, 490 US 730, 741 (1989).

64. Ibid at 751 .

65. Ibid at 742 .

66. See Seignette, supra (n 61) 134-8.

67. P Goldstein (ed), Goldstein on Copyright, supra (n 17) §4.3.2.0.

68. For example, in the British case of Hadley $v$ Kemp, judges referred to the control of 'how his songs should sound'. See Hadley v Kemp, EMLR 589 (Ch. 1999) at 641; and, in the American case of Thomson $v$ Larson, the judges explicitly noted 'An important indicator of authorship is a contributor's decisionmaking authority over what changes are made and what is included in a work', Thomson v Larson, 147 F.3d. 195 (2nd Cir. 1998), at 202-3.

69. Community for Creative Non-Violence et al. v Reid, 490 US 730, 751 (1989). 
For a work actually created by a non-human, for example strong AI beyond the tool sense, the authorship can be transferred from the actual creator (strong AI) to a person who had a control over the creative process.

To understand this theory, the following sub-sections will elaborate on what is the object of control and what would satisfy the sufficiency of control.

\subsubsection{The object of control: the creative process}

Creating a work typically entails several steps, commencing with a concept and ending with the fixation of the final expression. ${ }^{70}$ Thus, authorship can be regarded as a creative process. Further, the modern creative process from time to time involves numerous parties. In the process of authorship, machines, animals, and even humans, constantly operate or act under the direction and supervision of another. ${ }^{71}$

Under the 'control of the creative process' theory, control refers to control over the creative process, rather than over the outcome. The possible controller does not need to exercise direct control over the formation of expression of the work. In an era of creative specialization, the controller may not be able to control particulars of the creation; the control over the whole process, especially significant elements of the authorship process, matters more than trivial details. Emphasizing the control over the "creative process' is also a notable feature of this new theory.

\subsubsection{Sufficiency of control}

Control of the creative process does not need to be complete, but it does demand something more than just pressing a button to start. Determining sufficiency of control is vital to the application of the control theory in real cases. Professor Balganesh introduced the causation theory into copyright law, believing that the author's creation can be interpreted as a cause for copyright. ${ }^{72}$ The causation theory is also quite enlightening for the purpose of determining the degree of control in the context of copyright allocation. Causation mainly comprises two concepts: actual causation and legal cause, which a controller must satisfy before being considered an author.

The author proposes the following steps to weigh the sufficiency of control. First, the actual causation will be considered, using dominantly the 'but for' standard, ${ }^{73}$ where one's act is considered the cause of a result if the result would not have occurred 'but for' that act. ${ }^{74}$ To illustrate, in the case where if there is no condition ' $A$ ' it is impossible for the work to be realized, then 'A' constitutes an actual cause. Of course, this is only a rudimentary determination of causation and whether a controller is involved.

70. See S Balganesh, 'Causing Copyright' (2017) 117 Colum. L. Rev. 1, 64 (quoting Comput. Assocs. Int'l, Inc. v Altai, Inc. 982 F.2d 693, 697-8 (2d Cir. 1992)).

71. WT Ralston, 'Copyright in Computer-Composed Music: Hal Meets Handel' (2005) 52 J. Copyright Soc'y USA 281, 302.

72. See generally Balganesh, supra (n 70).

73. DW Robertson, 'Causation in the Restatement (Third) of Torts: Three Arguable Mistakes' (2009) 44 Wake Forest L. Rev. 1007, 1009.

74. See PM Coltoff, SA Giggetts, CM Gimeno, GK Harnad, JR Kennel and R Hatch et al. (eds), C.J.S. Negligence (Legal Encyclopedia, Thomson Westlaw 2017) vol. 65, § 220. 
The second step is to consider the legal cause of creation. In tort law, the "proximate cause' principle, known in English law as remoteness, ${ }^{75}$ has been developed. Generally, with the potential to trigger legal liability, the proximate cause is a substantial factor for the outcome. According to Black's Law Dictionary, proximate cause is 'a cause that is legally sufficient to result in liability; an act or omission that is considered in law to result in a consequence, so that liability can be imposed on the actor' ${ }^{76}$ Since the enjoyment of legal right also means legal responsibility, the principle of proximate cause in tort law can also be applied to determine the sufficiency of control in the authorship process by analogy. According to the principle of proximate cause, the controller's control should have a decisive effect on the creative process.

The most prominent test for proximate cause is the foreseeability test, ${ }^{77}$ typically stated as 'those consequences are deemed immediate and proximate which a person of average competence, experience, knowledge, and sagacity, being in the situation of the person whose conduct is in question, and having the same opportunities of observation, reasonably might be expected to foresee as likely to follow on such conduct'. ${ }^{78}$ The US Courts recurrently affirm proximate cause 'determined on the basis of whether an ordinarily prudent person ought to have foreseen that some injury might occur' ${ }^{79}$ Similarly, in the UK, following the Wagon Mound (No 1) decision, the test of legal causation, that is, the remoteness, is also the foreseeability. ${ }^{80}$ In terms of copyright, control is the legal cause of the result, that is, a copyrightable work. The degree of sufficiency of control can also be characterized by foreseeability, namely whether a reasonable person exercising the same or similar degree of control in the same or similar situations would foresee and anticipate an outcome of creation.

In all, a general principle can be formulated for assessing the sufficiency of control: the controller has determinative control over the creative process, and has reasonably foreseen and expected the result.

\subsubsection{Justifying the new theory}

First, this theory can find support from the origin of the concept of author. After the Renaissance in Europe, the romanticist notion of 'artist as creative genius' began to emerge and gradually came to dominate, influencing the basic structure of the copyright system. However, before the advent of romanticism, the creative talents of the author were not emphasized. ${ }^{81}$ The sculptures, paintings and music now regarded as typical

75. See SR Perry, 'Responsibility for Outcomes, Risk, and the Law of Torts', in Gerald J Postema (ed), Philosophy and the Law of Torts (Cambridge University Press 2001) 95.

76. BA Garner (ed), Black's Law Dictionary (9th edn, Thomson Reuters 2009) 250.

77. See RL Haig (ed), Business and Commercial Litigation in Federal Courts (4th edn, Thomson Westlaw 2017) vol. 5, § 47:21; see also Balganesh, supra (n 70) at 62.

78. L Dietz, A Jacobs, T Leming, L Martin, J Shampo, E Surette and L Zakolski (eds), American Jurisprudence (2nd edn, Thomson Westlaw 2018) vol. 57A, § 476.

79. See BA Lindah (ed), Modern Tort Law: Liability and Litigation (2nd edn, Thomson Westlaw 2017) vol.1, § 5:6.

80. See Overseas Tankship (UK) Ltd v Morts Dock \& Engineering Co Ltd (The Wagon Mound No.1) [1961] AC 388.

81. See SM O'Connor, 'Hired to Invent vs. Work Made for Hire: Resolving the Inconsistency Among Rights of Corporate Personhood, Authorship, and Inventorship' (2012) 35 Seattle U. L. Rev. 1227, 1235-6. 
works of art were then regarded as imitations of pleasing aspects of nature. ${ }^{82}$ Fables, poems and other literary works were also mainly about passing on moral emotion rather than intellectual creation. ${ }^{83}$ What are viewed as typical intellectual creations nowadays were not originally seen as the embodiment of an author's creativity and individuality. At that time, 'author' did not necessarily mean a natural person who creates a work, but may have referred to a person who designates, controls or dominates the creation. ${ }^{84}$ It can be seen that the concept of author initially implicated the element of control so that the control theory of authorship is well supported by the term's original meaning.

Second, the concept of authority (control) is also in line with modern theories of art. According to the institutional theory of art, as a powerful alternative to the concept of solitary authorship of romanticism, authority is a key component of authorship. ${ }^{85}$ Therefore, authorship 'can be satisfied by activities such as planning or delegation' ${ }^{86}$ The control theory of authorship can well coordinate the concept of authorship in law and art.

Third, this theory can be justified by the doctrine of intangible property. In essence, an intangible property right is a right to control instead of one to occupy. The expression 'control' is also employed in the context of intangible property, where the right to control is 'the intangible rights by another name'. ${ }^{87} \mathrm{So}$, the intellectual property right is a right of control over intangible objects. For the purpose of copyright, the right holder's control over intangible property is manifested via rights of reproduction, distribution, broadcasting and dissemination, and other exclusive rights. Thus, copyright is essentially a right to control. With the 'control of the creative process' as the exchange for 'the control of creative results', the control theory could be integrated into current doctrine in a balanced and reasonable way, and therefore justifies the controller of the creative process as the right holder.

\subsubsection{The systematic and rational advantages of the new theory}

First, the 'control of the creative process' theory can provide a systematic explanation for the allocation or assignment of authorship. Under traditional circumstances where copyright belongs to the actual creator, 'control of the creative process' theory can be understood as the actual creator himself has exerted sufficient control over the creative process; under the circumstances of transferring initial authorship from an actual creator to a legally constructive author, the entity who has imposed sufficient control over the creative process is the constructive author. With regard to both situations, such a 'controller as author' principle provides a rightful and consistent formula for copyright allocation.

Second, the 'control of the creative process' theory follows the logic of common sense. In the creation of works, monetary investment is neither the end nor the essence but merely the means, while its essence lies in the control of the creative process. A theoretical explanation focused on the essence is undoubtedly more rational and legitimate.

82. See PO Kristeller, 'The Modern System of the Arts: A Study in the History of Aesthetics

(I)' (1995) 12 Journal of the History of IDEAS 496, 497.

83. See O'Connor, supra (n 81) at 1236.

84. Ibid.

85. See Biron and Cooper, supra (n 56) at 55-85.

86. Ibid at 77.

87. Toulabi v United States, 875 F.2d 122, 125-6 (7th Cir. 1989). 
Third, the 'control of the creative process' theory well conforms to the incentive theory of copyright law. Among the justifications of intellectual property, incentive theory is the most powerful and widely accepted one. This theory should not be limited to the creation itself, but should concern the whole creative process or creative activity; more accurately, it could be modified accordingly as the 'incentive of creative process' theory, liberating intellectual property law from the swings between stimulating innovation and protecting investment. The incentive theory should focus on the process of creation, the controller of which should therefore be incentivized by the prospect of acquiring property rights.

Fourth, because of its systematic and rational advantages, this new theory can effectively cope with new challenges from emerging technologies. As discussed below, the question of how to attribute copyright for AI-created works can find a reasonable solution under this theory.

My conclusion is that the origin of the concept of authorship, the modern theories of art and the theory of property rights provide a solid basis for the controller of creative process to act as the original copyright holder. The 'control of the creative process' theory, which conforms to basic principles of property law and copyright law, can well provide a theoretical justification for the transfer of authorship from one to another, and it is a systematic and rational explanation of the ascertainment of authorship and the allocation of copyright. It is also inherently harmonious with the incentive theory and adaptable to new problems.

\section{AUTHORSHIP ALLOCATION OF AI CREATIONS: A NEW APPROACH}

The 'control of the creative process' theory can provide a new solution to the authorship allocation of AI creations. Before applying this new theory to AI-created works, this article intends to firstly examine a preliminary question of whether AI-created works should enjoy copyright protection.

\subsection{A preliminary question: AI-created works should enjoy copyright protection}

\subsubsection{AI creations may satisfy the originality requirement}

Under copyright law, AI-generated outputs need to meet the basic requirement of originality in order to obtain copyright protection. This requirement of originality is universal, as the Berne Convention stipulates that copyright protection is available to 'original works' ${ }^{88}$ Although originality is a general requirement, the criteria for determining it vary from jurisdiction to jurisdiction.

Noticeably, and most typically, there are at least three tests for originality, as follows: the UK's traditional 'skill and labour' test; the US's 'a modicum of creativity' test; and the EU's 'author's own intellectual creation' test, in which the personality ingredient is included, according to the European Court's jurisprudence. The personal nature of the EU's originality requirement is basically modelled on the Continental European civil law approach that has considerable influence and is followed by many other jurisdictions. For example, the Chinese judicial practice also

88. See Berne Convention for the Protection of Literary and Artistic Works, supra (n 12), arts 8 , 11 and 11 ter, etc. 
generally incorporates the criterion of 'a reflection of personality' into the concept of originality. 89

According to the UK's long-standing 'skill and labour' doctrine, ${ }^{90}$ there is no room for personality in the judgement of originality, and there is a de minimis rule for the required amount of skill and labour. ${ }^{91}$ Similarly, the author's individual personality plays no role in the US copyright law. In the US, the Copyright Act similarly requires that 'it must be an original work' in order to be protected by copyright, ${ }^{92}$ and originality is 'the touchstone of copyright protection'. ${ }^{93}$ According to the dominant standard established by the Feist case, 'Originality requires independent creation plus a modicum of creativity'. ${ }^{94}$ These minimum requirements seem to be very amenable to AI creations. However, traditionally, both the 'skill and labour' and the creativity are associated with natural persons, which is problematic for AI in terms of originality and authorship.

EU Copyright Directives mandate that works such as computer programs, databases and photographs should be the 'author's own intellectual creation' to meet the originality requirement. ${ }^{95}$ The Court of Justice of the European Union (CJEU) has made efforts to harmonize the originality standards in several important decisions. Firstly, the Infopaq decision made a 'horizontal' expansion of the 'author's own intellectual creation' requirement to all types of original works. ${ }^{96}$ Secondly, in decisions such as Paier and Football Dataco, the CJEU introduced the personality test into EU copyright jurisprudence by emphasizing the importance of stamping an author's 'personal touch' on the work. ${ }^{97}$ As long as the author is able to express his creative ability through 'free and creative choices', 'personal touch' can be established. ${ }^{98}$ However, if the production of the work 'is dictated by technical considerations, rules or constraints which leave no room for creative freedom', the originality standard cannot be satisfied. ${ }^{99}$ The EU term 'author's own intellectual creation' is not a term borrowed directly from the UK copyright law or Continental European droit d'auteur system. This abstract term may reflect some degree of compromise between these different

89. See, for example, 'Case 4: Hu Sansan v. Qiu Haisuo and China Art Galler', in L Zhou (ed), China Court Cases on Intellectual Property Rights (Kluwer Law International 2011) 63.

90. See, for example, University of London Press v University Tutorial Press [1916] 2 Ch 601, at $609-10$.

91. See A Rahmatian, 'Originality in UK Copyright Law: The Old "Skill and Labour" Doctrine Under Pressure' (2013) 44 IIC 4, 14.

92. See 17 USC. $§ 102$ (a) (1988).

93. Feist Publications, Inc. v Rural Tel. Serv. Co., 111 S. Ct. 1282, 1295 (1991).

94. Ibid at 1288 .

95. See Council Directive 91/250/EEC of 14 May 1991 on the legal protection of computer programs [1991] OJ L122/42, art 1(3); Directive 96/9/EC of the European Parliament and of the Council of 11 March 1996 on the legal protection of databases [1996] OJ L77/20, art 3(1); Directive 2006/116/EC of the European Parliament and of the Council of 12 December 2006 on the term of protection of copyright and certain related rights [2006] L372/12, art 6.

96. Case C-5/08 Infopaq International v Danske Dagblades Forening [2009] ECR I-6569, paras 33-7.

97. C-145/10 Eva-Maria Painer $v$ Standard VerlagsGmbH and Others (Third Chamber) [2011] ECR I-12533, paras 88-92; C-604/10 Football Dataco v Yahoo! UK Ltd (Third Chamber) [2012] ECDR 10, para 38.

98. Ibid.

99. C-604/10 Football Dataco v Yahoo! UK Ltd (Third Chamber) [2012] ECDR 10 ('Football Dataco'), para 39. 
legal systems. However, the CJEU has constantly endorsed the view of the droit d'auteur system to understand originality as a reflection of personality.

The most problematic test for AI creations is the personality test, which is popular in civil law countries and is also reflected in the EU's originality jurisprudence. If the originality must presume personality or personhood, there is no room for further discussion. Under the UK's traditional test, labour, skill and creative judgements of an artistic kind originate from a natural person. The same is true for 'a modicum of creativity' in the US. Under each test, AI may constitute a challenge to traditional theories and practice that needs to be resolved.

There are two approaches to solving this problem. One is the exceptional approach. The British rule on CGWs seems to follow this approach. Under the British rule, as Ramalho observed, 'the originality requirement will have to be self-standing and independent of authorship'. ${ }^{100}$ Guadamuz also commented that the UK rule 'acts as an exception to the originality requirements in copyright law'. ${ }^{101} \mathrm{By}$ simply taking it as an exception, there is no need to scrutinize the labour and skill input or creative effort of the deemed author.

Another approach is through a liberal construction of originality, rather than a strict or conservative construction of it. The originality standard evolves; moreover, in the face of the challenges of AI creations, it is necessary to make a little adjustment to it. First, the originality requirement should thus be understood objectively to exclude its personality ingredient. Yanisky-Ravid and Velez-Hernandez recommended a more formal and objective approach to originality as opposed to the existing subjective or mixed approaches. ${ }^{102}$ Indeed, it is better to examine originality in an objective way and focus on the results of creation, not the process. As the term 'original works' in the Berne Convention indicates, the originality should be present in a work so that it can be perceived objectively. Should creations generated by AI be indistinguishable from human creations that possess originality, both shall be deemed as having met the standard of originality. Second, with regard to 'free and creative choices', which is key in the EU jurisprudence of originality, in the case of sophisticated strong AIs that imitate the human nervous system, they may have the ability to make creative choices and judgements, although confined by certain rules and parameters. With the development of deep learning technology, artificial neural networks can learn, discover and even formulate rules and parameters by themselves. The outputs of these AIs are not simply mechanical, nor completely pre-determined by the programmer, but could embody AI's free and creative decisions. As long as we recognize the intelligence of AI, it is not a problem for AI to be confined by rules and parameters, because humans also need to follow certain mental rules and logics in order to think and act in a reasonable way. Therefore, if we exclude the personality ingredient, AI's intelligence and creativity can be accredited. Looking objectively, creative choices can be embodied in works created by AI, but such choices are conducted by a machine that cannot hold legal rights or assume legal responsibilities. The ideal solution is to consider the initiator and controller of the AI creative process as the originator of such creative decisions. In other words, the AI is just an agent for creation. Third, alternatively, in some situations, a person may directly satisfy the originality requirement because of

100. Ramalho, supra (n 4) at 17.

101. Guadamuz, supra (n 3) at 177.

102. See S Yanisky-Ravid and LA Velez-Hernandez, 'Copyrightability of Artworks Produced by Creative Robots and Originality: The Formality-Objective Model' (2018) 19(1) Minn. J.L. Sci. \& Tech. 1. 
his or her involvement in the process of AI creation. As mentioned, the originality standard, or a 'threshold' to copyright protection, is sufficiently low. It does not demand the same level of novelty or innovation as required by patent law. Main jurisdictions in the world, including the UK, the US, France and Germany, have historically adopted a minimal standard of originality. ${ }^{103}$ Thus, even a minimum human involvement in the process of AI creation may satisfy the originality requirement. Traditionally, human authorship denotes forming or shaping expression or elements by selection, arrangement or other means. ${ }^{104}$ In the Infopaq case, the CJEU determined that the choice, sequence and combination of words in text snippets satisfied the originality requirement of 'intellectual creation'. ${ }^{105}$ As one commentator has argued, 'selection, in combination with constructing the circumstances that led to the existence of the work' can constitute a human being's originality in machine creations. ${ }^{106}$ If human intervention in AI creations fits the described pattern - for example, selecting, arranging, shaping, polishing and fixing the final outputs may satisfy the originality requirement ${ }^{107}$ - the contribution of AI would not hinder such works from copyright protection. In such cases, the human element in AI creations meets the minimum requirement of originality.

The conclusion therefore is that AI-generated outputs may satisfy the originality requirement and become copyrightable works. Meanwhile, it is worth noting that although the originality requirement is only a minimum one, it does exist. In the case of works generated by a machine "without any creative input or intervention from a human author', as asserted by the US Copyright Office, such works should not be protected by copyright. ${ }^{108}$

\subsubsection{AI creations should enjoy copyright protection}

Legal disputes over newly proposed questions should not be confined to the superficial application of legal rules. On the contrary, it is their underlying theories that should be further scrutinized. I further argue here that, even from a theoretical perspective, AI creations should enjoy copyright protection.

First, the essential purpose of the copyright system is to promote both the creation and the dissemination of works, and thus to advance the progress of society. From a teleological perspective, the public has no substantial interest in who owns the copyright. Rather, what concerns the public is whether the work is publicly available. Since AI-created works would enrich information in the fields of literature, arts and sciences and promote social welfare, affording copyright protection to these works would stimulate the creation and the dissemination of information. From an instrumentalist perspective, both 'incentives to innovation' and 'incentives to dissemination' are equally important. Consequently, if the law refuses to protect the creations of AI, at least it will not be conducive to the dissemination of AI creations.

103. See Dutfield and Suthersanen, supra (n 14) at 80.

104. See US Copyright Office, Sixty-Eighth Annual Report of the Register of Copyrights for the Fiscal Year Ending June 30, 1965 (The Library of Congress, Washington, DC 1966) 5.

105. Case C-5/08, Infopaq Int'l A/S v Danske Dagblades Forening, 2009 E.C.R. I-06569, §45.

106. NF Burstyn, 'Creative Sparks: Works of Nature, Selection, and the Human Author' (2015) 39 Colum. J.L. \& Arts 281, 283.

107. See P Samuelson, 'Allocating Ownership Rights in Computer-Generated Works' (1986) 47 U. Pitt. L. Rev. 1185, 1203.

108. US Copyright Office, Compendium, supra (n 22) § 313.2. 
Second, if copyright protection is refused for AI creations, it will inevitably lead to a situation where the actual controller of AI publishes the generated outputs in his or her own name and thus denies the AI's due publicity. In this case, it is the 'wrong' individual's creative talent that is evaluated. Such a result seriously deviates from the basic theory of copyright law. Luckily, by recognizing and giving direct copyright protection to AI-created works and designing a set of rational rules for this category of special works in line with traditional principles, legislators and/or judges could avoid such an unintended situation.

After establishing that AI-created works are copyrightable, the difficult question remains: who should be the author and/or the copyright owner?

\subsection{Problems of existing approaches of authorship allocation}

Debates on the AI authorship issue can be traced back to discussions of copyright for CGWs several decades ago. Up to today, the issue is far from resolved. After a long period of discussions, there are at least five options for copyright allocation in AI-created works. This article will review them one by one.

The first option is to place works created by AI in the public domain. ${ }^{109}$ However, with no one stimulated to disseminate and promote these AI-created works for the purpose of profiting from copyright, the availability of AI-generated copyrightable works would be decreased, making this approach counterproductive. ${ }^{110}$ In addition, this approach would suffer from enforceability issues. The owner of an AI system, usually the direct controller of the raw output generated by AI, would tend to make the output his own. The controller may intentionally withhold the truth that the work was produced by AI, which is quite doable.

The second option is to grant authorship to an AI-equipped machine or computer. For instance, one scholar has earlier argued that the computer should be regarded at least as a co-author in the case of autonomous machine creation. ${ }^{111}$ However, copyright law has never anticipated machine authorship. It is generally held that the author in the copyright context should be a natural person or at least a juridical person. Simply put, a computer or machine does not have the personhood necessary to claim a copyright.

The third option is the user approach. Traditionally, for CGWs, one view is that the user who employed the computer shall be the author. ${ }^{112}$ However, positioning an AI as an inert tool may no longer be sound, with technology evolving and AI becoming increasingly capable and autonomous. While weak AIs are traditionally used as a tool, stronger or more sophisticated AIs will no longer be an inert tool in this traditional sense. For the latter case, the instrumentality does not justify the allocation of authorship and copyright to the user, as in the former case.

The fourth option is the programmer approach. Some scholars have proposed that the programmer of an AI is the 'logical owner' of whatever content the AI generates. ${ }^{113}$

109. See, for example, AH Khoury, 'Intellectual Property Rights for "Hubots": On the Legal Implications of Human-Like Robots as Innovators and Creators' (2017) 35 Cardozo Arts \& Ent. L.J. 635, 655.

110. See K Hristov, supra (n 1) at 439.

111. See KF Milde, Jr., "Can a Computer Be an "Author" or an "Inventor" (1969) 51 J. Pat. Off. Soc'y $378,393-5$.

112. See CONTU Final Report, supra (n 6) at 45.

113. See, for example, A Bridy, 'Coding Creativity: Copyright and the Artificially Intelligent Author' (2012) 5 Stan. Tech. L. Rev. 1, 21; Burstyn, supra (n 106) at 307. 
However, under this approach, the programmer would own an unlimited number of copyrighted works that are probably beyond the programmer's anticipation. In fact, in most circumstances, awarding copyright to the programmer is counterintuitive. It is the direct controller of the program, usually an owner or buyer of the program, instead of the programmer, who reasonably expects a legal right over the results of their use of the program. As pointed out by Professor Samuelson, the programmer just provides the potentiality for the creation, but not its actuality. ${ }^{114}$ Assigning rights to someone who only offers the possibility of creation will be a significant departure from the basic principles of copyright law.

The fifth option is the joint authorship approach. ${ }^{115}$ This approach sounds attractive, but it is not consistent with copyright principles. For joint authorship to be admitted, both parties must actually intend to be co-authors (as typical in the US law) or satisfy the requirement of collaboration (as typical in the UK law). However, it is difficult to find mutual intent or collaboration between the AI and a person, and hard for it to exist between the user and the programmer, considering the usual distance between them.

It appears that the various existing answers to the question of authorship of AI creations are somewhat unsatisfactory. Recalling that a more appropriate answer should be supported by basic theories and doctrines of copyright law, this research will attempt to find a new solution to the AI authorship problem under the 'control of the creative process' theory.

\subsection{A new approach under the 'control of the creative process' theory}

\subsubsection{Necessary principle: AI under human control}

AI will become increasingly automatic and sophisticated; nevertheless, it shall act under the control of human force. AI may potentially surpass human intelligence in the future, but should and still could be reined in by human beings. The general principle of human control provides possibilities for humans to exercise sufficient control over the AI-involved creative process.

An AI-equipped computer or machine does not create itself. Naturally, a person activates and directs AI to create. AI's creative processes are activated or initiated by human beings, whereby it ordinarily follows instructions given by a controlling person. Further, the controller may contribute to selecting and improving the final product. The interaction between the person and AI constitutes a significant element in the 'authorship' process leading to the final product. ${ }^{116}$

The involvement of AI would be more prevalent in the creative industries and expedite the creative process. Nevertheless, the human ingredient could still be found in AI-created works. Behind every AI stands a person manipulating and controlling it. In short, AI is a controlled participant in the creative process.

However, if someone only supplies power to AI, or just presses a start button, it is difficult to meet the requirement of sufficiency of control and also hard to say that it is a control of the 'creative process'. As in the traditional sense, a person who just supplies power to a computer cannot be the author of whatever the computer produces. The following subsections will elaborate on who should be considered the controller of the creative process under different circumstances.

114. Samuelson, supra (n 107) at 1209.

115. See, for example, Kaminski, supra (n 7) at 595.

116. See Miller, supra (n 10) at 1067. 


\subsubsection{In general, the owner of AI is the controller}

Suppose the owner and the programmer of an AI system are different persons, compared to the programmer, the owner of $\mathrm{AI}$ is usually the proximate or legal cause for the work to be produced. Although owners of AI do not directly contribute to the formation of the expression of a work, they still constitute the human elements that cause the work's creation. Under the 'control of the creative process' theory, the controller does not need to directly contribute to the creation of expression. As long as the person is in control of the creative process, this person should be considered as the proximate cause for the result.

Typically, as a person should activate and supervise the AI creation process, the owner is in control of key steps of the creative process, from the very beginning of the process to the ultimate shaping of the outcome, following the reasoning of one classic argument focused on the importance of 'initiating' the creation. ${ }^{17}$ Besides, the owner controls the creative process intentionally or unintentionally when selecting, reshaping, polishing and/or fixing the final outputs.

In summary, under most circumstances, the owner of an AI system should be considered as the author, as far as the owner has exerted sufficient control over the creative process.

\subsubsection{Exceptionally, the programmer would be the controller}

Remoteness could affect the sufficiency of control. The programmer, after selling or distributing their program usually is in a remote position with respect to the AI creations compared with the owner. However, the programmer could arrange a scheme of control retention in order to acquire follow-up benefit from the use of AI programs. After completing the program, the programmer could choose to keep the program to himself or sell it. Even if he chooses the latter option, if the value of the AI creations is foreseeable and significant, the programmer can retain control over the program by the following two methods.

The first type of control retention is 'contractual control'. Where the buyer is subject to a licensing agreement, the programmer could stipulate provisions of benefiting sharing and control retention by designing an enforcement mechanism in such an agreement.

The second type, 'technical control', could be employed concurrently with 'contractual control'. If programmers do not wish to lose copyright in works further generated by AI to buyers, owners or end users, they could impose technological measures to eliminate such possibilities and thus retain control. For example, where the AI's parameters and rules are controlled by the programmer and the output is determined by the programmer, the end user's contribution is nothing more than pushing a start button, and the result produced is therefore entirely under the control of the programmer. ${ }^{118}$ In this situation, considering the buyer, owner or user has no control over the AI program other than causing it to run, the programmer who has imposed sufficient control is entitled to claim copyright in the final product.

117. See RC Denicola, 'Ex Machina: Copyright Protection for Computer-Generated Works' (2016) 69 Rutgers U. L. Rev. 251.

118. See Ralston, supra (n 71) at 304. 


\subsubsection{Even if AI has legal personality, the authorship should be transferred to the controller}

In the future, the law may develop to a stage that an AI or AI-embedded robot may acquire legal status, which is possible considering the evolution of the juridical person in history.

If that happens, this article still holds that assigning authorship to the person behind AI is better than assigning it directly to an AI or an AI-embedded robot, mainly because a machine or robot does not respond to the incentive provided by copyright law, and what should be incentivized are the acts of a person to control the AIinvolved creative process. Such a solution would be consistent with the incentive theory, one of the basic theories of copyright law.

Such an arrangement would also provide a systematic and consistent solution to the AI authorship problem. No matter whether AI is used in a tool sense or in a non-tool sense, or even where it has legal personality, copyright in its creations can consistently be owned by the controller. This could avoid the time-consuming task of determining whether AI is a tool or not in borderline cases.

\subsubsection{Where there is no controller of the creative process}

Different levels of AI autonomy can (and do) exist and thereby affect the allocation of authorship. ${ }^{119}$ If $\mathrm{AI}$ evolves to a stage where its creative process requires little human involvement, who should be the author? Under the control theory of authorship, whether a person could claim copyright in AI-generated outputs depends on the degree of the said person's control in the creative process. Awarding copyright to a person with little control over the creative process also contradicts the fundamental policy that copyright protection functions as a mechanism to incentivize creation. ${ }^{120}$ Thus, autonomously generated outputs by AI with little human involvement in the creative process should belong to the public domain. Such a conclusion is also in line with the human authorship requirement, which does not support copyright protection for a work created by a non-human where the human element involved is almost or completely non-existent.

Overall, if there is no person exercising legally sufficient control over the creative process, the generated outputs should go into the public domain; however, as far as there is such a person, that person, either a natural or a juridical one, should be considered as an author.

\section{FURTHER OBSERVATIONS: COMPARATIVE LAW PERSPECTIVE}

The discussion above provides a theoretical analysis of the authorship of AI creations. As mentioned, international conventions have not harmonized the rules of authorship, with considerable divergences between the copyright system and author's right system. A detailed comparative analysis is beyond this research, yet several points should not be left unnoticed.

AI copyright issues are comparatively easier to solve under the common law system, as demonstrated by the pioneering British legislation on CGWs. ${ }^{121}$ This is indeed a

119. See Burstyn, supra (n 106) at 308.

120. See Ralston, supra (n 71) at 307.

121. See Copyright, Designs and Patents Act (Eng.), 1988, s 9(3). 
straightforward approach that conforms to common sense. ${ }^{122}$ However, there remain questions regarding the justification of this approach and the criteria for determining the qualification of necessary arrangements. These rules can be justified under the 'control of the creative process' theory, and, further, the test of sufficient control articulated by this article may be helpful to better understand the British approach. In addition, it is logical to extend the CGWs rules to AI creations because the British rule of CGWs is aimed at solving the 'circumstances such that there is no human author of the work', ${ }^{123}$ not just the situations of using computers as tools. Essentially, if the computer is just used as a tool, there is no need to make special provision for such works, because people have traditionally used tools to create. However, human intervention, whether through necessary arrangements under the UK law, or by sufficient control of the creative process, as this article advocates, should still exist so that one can become a deemed author of CGWs or AI creations.

Copyright law in the US, China and Japan might encounter more obstacles before providing an arrangement of authorship transfer for AI-created works based on the control theory. Fortunately, if the author of AI creations is the person who controls the creative process, the human authorship requirement can be maintained. Besides, such an approach is backed by the theory of authorship transfer implied by the works made for hire doctrine rooted in the laws of these countries. It should be emphasized that this article proposes that lessons be drawn from the underlying theory of the works made for hire rule, rather than directly resorting to the rule for solving the AI copyright problem.

Countries with a deeper tradition of civil law, such as Germany and France, face the severest challenges. Since in these countries the author's right is theoretically linked to personhood, and authorship only vests in the individual, a legal person by default cannot be the author and the first holder of the copyright. ${ }^{124}$ Worse still, these jurisdictions do not generally recognize the works made for hire doctrine. However, at least for computer programs, the EU Computer Program Directive has introduced the works made for hire doctrine, ${ }^{125}$ inevitably affecting these civil law countries, including Germany and France. ${ }^{126}$ Foreseeably, AI-created works, along with a specific arrangement for authorship, also demand and are indeed worth special care. Meanwhile, if other influential jurisdictions, such as the UK (already providing copyright protection to CGWs), the US, China and Japan, grant copyright protection to AI-created works, these civil law countries might follow to avoid imaginable loss in foreign markets that may discourage the development of the AI industry and impair the competitiveness in the emerging technologies of these countries.

\section{CONCLUSION}

Current copyright theory and doctrines present great adaptability in the context of AI creations, even for sophisticated AI beyond the tool sense. A 'control of the creative

122. Miller, supra (n 10), at 1052-3 (stating 'British copyright law takes the commonsense approach that the absence of a human author is no impediment to protection').

123. Copyright, Designs and Patents Act (Eng.), 1988, s 178.

124. See Copyright Act 1965 (Germany), last amended September 2017, ss 2(2) and $7<\mathrm{https} / / /$ www.gesetze-im-internet.de/englisch_urhg/> (English translation) accessed 16 January 2020; Intellectual Property Code 1992 (France), arts L112-1 and L 113-1 <https://www.wipo.int/ edocs/lexdocs/laws/en/fr/fr467en.pdf> (English translation) accessed 16 January 2020.

125. See Directive 2009/24/EC of the European Parliament and of the Council of 23 April 2009 on the legal protection of computer programs, [2004] OJ L111/16, art 2(3).

126. See Copyright Act (Germany), s 69b; Intellectual Property Code (France), art L113-9. 
process' theory can be established based on existing rules of authorship transfer in modern copyright law, to satisfactorily answer the challenges of AI creation for copyright law. The person, either a natural or a juridical one, who has legally exercised sufficient control over the creative process should be constructed as an author of the outcome.

Although national laws vary with the concept of author and authorship, the proposed solution could be adopted and implemented by countries from different copyright traditions with support from their respective theories and policies. Finally, the borderless nature of technology may encourage the convergence of legal systems in terms of technology and law. 